\title{
The role of conversation in coping with the psychosocial situation of dealing with cancer
}

\author{
Solveig Nelly Sægrov* \\ Western Norway University of applied Science, Førde, Norway
}

Received: May 5, 2019

DOI: $10.5430 /$ jnep.v9n10p122
Accepted: July 12, 2019

URL: https://doi.org/10.5430/jnep.v9n10p122

\begin{abstract}
Objective: In this Scoping study, the purpose is to examine and describe what the research literature reports on the use of professional conversation as a tool for helping people with cancer cope with the psychosocial situation. The cancer patient may experience several side effects and symptoms related to treatment and illness, and may have a need for more support through professional conversation.

Methods: Scoping study with searches in the following databases: PubMed, Cinahl, Psyclfo, Academic Search premier, Cochrane and Ovid.

Results: Twenty-nine studies were examined in the initial search, and twenty-four of them were included. Six examined the cancer patient's needs for conversation, thirteen nurses' qualifications, and five whether conversation provides support. One factor that clearly emerges from the findings of several of the studies is that many nurses experience communication barriers in their encounters with cancer patients.

Conclusions: The findings indicated a strong need for conversation. One surprising finding was the communication barriers experienced by nurses/health care professionals.
\end{abstract}

Key Words: Scoping study, Cancer patient, Conversation, Psychosocial situation, Nurse, Communication barriers

\section{INTRODUCTION}

Around 30,000 people are diagnosed with cancer every year in Norway. ${ }^{[1]}$ This means that there are many people living with this illness, and around $60 \%$ of those who develop cancer survive. ${ }^{[2]}$ Several studies found that cancer patients seek support in the difficult convalescence period after undergoing treatment. ${ }^{[3-6]}$ Most people who are diagnosed with cancer undergo gruelling medical treatment. Research shows that around $70 \%$ of all patients with cancer suffer from a certain level of fatigue, which is characterised by a feeling of exhaustion that cannot be alleviated by rest. ${ }^{[7-9]}$ Illness, suspicion of illness, and the risks of spread or relapse threatens the pa- tient's sense of security. ${ }^{[10]}$ The challenge for the patient is to find out how to move forward in the recovery process. Conversation may be the most important community-building tool we have. The experience of hearing what the other has to say and responding to it with new questions. ${ }^{[11]}$

A study conducted by Måtar ${ }^{[12]}$ shows that discussing difficult subjects can be experienced as demanding and unpleasant, and that it takes courage to deal with patients in the right way. It takes courage to raise existential issues and to address the other person's anxieties. Courage is the ability to respond to and deal with difficult situations, to take responsibility for one's actions and beliefs. ${ }^{[13-15]}$ \footnotetext{
Norway.

*Correspondence: Solveig Nelly Sægrov; Email: Solveig.Nelly.Segrov@hvl.no; Address: Western Norway University of applied Science, Førde,
} 
Research question: In this paper we explore theoretically what the research literature reports on the use of professional conversation as a tool for helping people with cancer cope with the psychosocial situation.

\section{MethodS}

There are many types of literature reviews, and no consensus exists on what characteristics or criteria form the basis for each type. The method selected for this review was a scoping study. ${ }^{[16-18]}$ According to Arksey and O'Malley ${ }^{[16]}$ and Polit $\& \mathrm{Beck}^{[18]}$ the main differences between a systematic literature review and a scoping study is that in a scoping study the research question is less specific, more sources are used to identify relevant studies, studies with different designs and methods are included, and the inclusion criteria are defined after the literature searches are completed. The objective of a scoping study is to given an overview of the research field and a descriptive presentation of key information in the articles included. Thus, a scoping study will not contain a summary or synthesis of evidence nor asses the quality of the level of evidence as one normally expects of a systematic literature review or meta-analysis. A scoping study was selected as the method for this study because the communication research field is limited, even though the cancer research field is large. The search words that were used for inclusion of articles were: "psychosocial", "conversation", "communication" and "cancer".

The literature searches were conducted in October 2014 in the following databases: PubMed, Cinahl, Psyclnfo, Academic Search Premier, Cochrane and Ovid. The searches were not refined with respect to design, method or outcome measures. While the searches were being conducted, the studies were carefully reviewed with respect to objective, design, sample and findings/conclusion. Twenty-nine studies were examined in the initial search, and twenty-four of them were included. Of these were four literature study article. That means second-hand accounts of events or facts: in research, a description of a study prepared by someone other than the original researcher. ${ }^{[18]}$ According to Polit and Beck $^{[18]}$ a literature review is similar to doing a quality study, particularly with respect to the analysis of data. In both, the focus is on identifying important themes. In this review six articles examined the cancer patient's needs for conversation, thirteen nurses' qualification, and five whether conversation provides support.

\section{Findings}

The key information in the articles is presented in Appendix 1. The studies were divided into three thematic groups based on content, objectives and findings:

Published by Sciedu Press
1) The patient's need for professional conversation.

2) The nurse's qualifications.

3) Conversation gives support.

\subsection{The patient's need for professional conversation}

Cancer patients reported a need to talk to someone with knowledge of their disease and treatment and they wanted psychological support. They expressed unmet informational needs. Online communication appears to serve an impact function.

Research shows that despite the increased focus on rehabilitation in cancer treatment programmes, cancer patients frequently have unmet needs during the early cancer trajectory. ${ }^{[19]}$ They have a need to be the main character in their life's drama; a need to be an active participant and mobilise their strength; and a need for storytelling and exchanging of experiences. ${ }^{[20]}$ Cancer patients reported a need to talk to someone with sufficient knowledge of their disease and the treatment side effects, as well as a need for services that are easy to find and use. ${ }^{[20]}$ In their study Merckaert et al. ${ }^{[21]}$ found that one of four women and one of 10 men wanted psychological support. The patients also wanted to talk about normal life, their hobbies and their families. Such conversation seems to support their coping strategies. ${ }^{[22]} \mathrm{A}$ review Jansen et al. ${ }^{[23]}$ of the specific needs of older patients with cancer in the treatment phase of the disease showed that many older patients wanted as much information about the disease and treatment as possible, but were less interested in the details than younger patients.

Cancer patients used online communication to ask questions and express concerns about symptoms, fear of relapse, uncertainty in everyday life. ${ }^{[24]}$ However, patients expressed experiences of being "left in a void" after being discharged from hospital and living with serious unmet informational needs. According to Foster et al. ${ }^{[25]}$ the mobiles appear to serve an important function in providing information and support in the community where visitors can drop in for an informal conversation with trained members of staff to ask question and receive support in relation to cancer.

\subsection{Nurses' qualifications in conversations with cancer patients}

Nurses are viewed as a source of information during and at the end of treatment. According to a study there was a tendency by surgeons to move from issues of psychosocial nature to clinical matters. There are identified challenges in conversation and there are pointed out that nurses needs training in nurse - patient communication in oncology care. Large - scale survey predict the anxiety of nurses related to cancer nursing. 
Boot and Wilson ${ }^{[26]}$ identified three key challenges in conversations: (1) Assessing whether the patient was ready to discuss the topic; (2) the patient's physical condition, and (3) the nurse's relationship with the patient and family. According to Zamanzadeh et al. ${ }^{[2]}$ and Waldron et al. ${ }^{[2]}$ nurses must receive proper training that meets their needs and that focuses on a holistic and patient-centred approach. This will influence nurse-patient communication in oncology care. In a study the nurses identified key barriers to patient-centred communication. ${ }^{[29]}$ From qualitative interviews Brataas \& Thorsnes ${ }^{[30]}$ it emerges that oncology nurses believed that having the freedom to act in interplay with patients' voices, the patients' perspectives becomes foregrounded. According to Yoon et al. ${ }^{[31]}$ there was a tendency by the surgeons to move from issues of psychosocial nature to clinical matters. Patient participation in decisions regarding surgical treatment were viewed as limited. ${ }^{[32]}$ In a study of Koutsopoulou et al. ${ }^{[33]}$ nurses are viewed as a key source of information during and at the end of treatment.

Indou $^{[34]}$ conducted a large-scale survey to predict the anxiety of nurses related to cancer nursing and refers to factors such as negative experience of nursing patients at the time of death, the feeling of the gap in goals for cancer nursing, the emotional necessity to provide care with a business-like attitude, the attitude which avoids using the world 'death' in conversation, the negative cancer image, and the failure of execution of the informed consent of the nurse. A review study of Radziewicz et al. ${ }^{[35]}$ shows rigorous measurement of interventionist adherence to the intervention protocol and flexibility to allow for changing needs of patients and family caregivers. The enterostomal nurses found that telephone follow-up after a patient's hospital discharge was meaningful work. ${ }^{[36]}$ The article of Farrington and Towsend ${ }^{[37]}$ shows that critical reflection is a valuable learning process.

\subsection{Conversation gives support to cancer patients}

The findings from these studies shows that patients are satisfied with the nurses' clinically based conversation.

Uitterhoeve et al. ${ }^{[38]}$ used a questionnaire and videotaped interviews with many patients and some nurses. The findings show that nurses' cue responses were appreciated by the patients. One study of Koinberg, Holmberg \& Fridlund ${ }^{[39]}$ showed that patient satisfaction with the knowledgeable and professional skills of the nurses was high. Another study IMA et al. ${ }^{[40]}$ identified acceptance and valuation by the clientele of nurses' clinically based conversations. With respect to developing an understanding of nursing from the perspective of caring in nursing from the perspective of cancer patients through 20 interviews Liu, Mok \& Wong, ${ }^{[41]}$ the findings showed that caring in nursing as perceived by cancer patients involves nurses having qualified professional knowledge, attitudes and skills in oncology and providing the informational, emotional and practical support and help required by cancer patients. According to the study of De Araujo and Rosas ${ }^{[42]}$ the findings identified acceptance and valuation by the clientele of nurses' clinically based conversation.

\section{Discussion}

Despite the increased focus on information to cancer patients and lack of it, there has been less focus on conversation as a tool, a tool that should accommodate information. The reason for this may be that it can be difficult to measure the direct effects of conversation. The literature shows that some studies have been conducted on conversations by telephone, video recordings, and on questions addressed to experts and posted on social media.

Cancer patients use online communication to ask questions and express concerns about symptoms, experiences, fear of relapse, and uncertainty in everyday life. ${ }^{[24]}$ However, patients expressed experiences of being "left in a void" after being discharged from hospital also living with serious unmet informational needs.

The most surprising finding in the Scoping review was the studies conducted on the qualifications and perceived challenges of nurses/health care professionals in conversations with cancer patients. Several reported experiencing communication barriers in their encounters with patients. Nurses need training and measures to overcome communication barriers. ${ }^{[36]}$ Discussing difficult subjects can be experienced as demanding and unpleasant, and that it takes courage to deal with patients in the right way. ${ }^{[12]}$

Several studies on conversations between nurse and patient in the literature review show that there was a high level of patient satisfaction with the nurses' knowledge and professionalism. The nurses' cue responding was appreciated. This is important to note because conversation is the most important community-building tool we have. ${ }^{[11]}$

\subsection{Strength and limitations of the methods}

The strength of the method in this study is that objective of a scoping study is to given an overview of the research field and a descriptive presentation of key information in the articles included. ${ }^{[16,18]}$ In this study there is one table (see Appendix 1) that presentate an overview of articles, included in the respective studies. The information also is presentated under each category and findings.

In this study the limitation of scoping review is, may be, that the research question is less specific than it would have 
been in a systematic literature review. Studies with different designs and methods are included. Thus, a scoping study will not contain a summery or synthesis of evidence as one normally expects of a systematic literature review or metaanalyses. ${ }^{[16,18]}$

A limitation can also be the four review articles witch are secondary source and descriptions of studies prepared by someone other than the original researcher. ${ }^{[18]}$ Secondary sources are not substitutes for primary sources because they typically fail to provide much detail about studies, and are seldom completely objective. On the other side, if the review studies are recent, they are a good place to start because they provide an overview of the topic and valuable bibliography. ${ }^{[18]}$ In this study the secondary sources are not quite new, but still topical.

\section{Conclusion}

This Scoping review shows that cancer patients who take part in professional conversations with nurses are satisfied with their knowledge, support and professionalism. Another factor that clearly emerges from the findings of several of the studies is that many nurses experience communication barriers in their encounters with cancer patients. This is something that must be addressed in terms of both training and research.

\section{Conflicts of InTEREST Disclosure}

The author declares that there is no conflict of interest.

\section{REFERENCES}

[1] Cancer registry of Norway. Cancer in Norway, 2013. Cancer registry of Norway, Institute of Population-based Cancer Research, Oslo. 2015.

[2] Loge JH, Dahl AA, Fosså SD, et al. Cancer survivors: New knowledge and possibilities from a long-term perspective. Gyldendal Akademisk, Oslo. 2013.

[3] Pattison NA, Doland S, Townsend P, et al. After critical care: a study to explore Patients' experiences of a follow-up service. Journal of Clinical Nusing. 2007; 23(1): 40-3.

[4] Wilson K, Pateman B, Beaver k, et al. Patient and carer needs following a cancer-related hospital admission: the importance of referral to the district nursing service. Journal of Advanced Nursing. 2002; 38(3): 245-253. https ://doi.org/10.1046/j.1365-2648. 20 $02.02173 . \mathrm{x}$

[5] Vivar CG, Mcqueen A. Informational and emotial needs of longterm survivors of breast cancer. Journal of Advanced Nursing. 2005; 51(5): 520-528. PMid:16098169 https ://doi.org/10.1111/j . 1365-2648.2005.03524.x

[6] Mckenzie H, Boughton M, Hayes L, et al. University of Sydney. Journal Compilation. 2007; 15(4): 352-359. PMid:17578396 https://doi.org/10.1111/j.1365-2524.2007.00694.x

[7] Readdy S, Bruera E, Pace E, et al. Clinically important Improvement in the intensity of fatigue in patients with advanced cancer. J Palliate med. 2007; 16: 2122-2131.

[8] Stone PC, Minton O. Cancer-related fatigue. Eur J Cancer. 2008; 44(8): 1097-104. PMid:18381237 https://doi.org/10.1016/j. ejca. 2008.02.037

[9] Davis MP, Goforth HW. Long-term and Short-term Effects of Insomnia in Cancer and Effective Interventions. Cancer Journal (CANCER J). 2014; 20(5): 330-44. PMid:25299143 https ://doi .org/10.1 $097 / \mathrm{PPO} 0.0000000000000071$

[10] Mollica M, Nemeth L. Transition From Patient to Survivor in African American Breast Cancer Survivors. Cancer Nursing (CANCER Nurs). 2015, Jan-Feb; 38(1): 16-22. PMid:24406383 https : //doi.org/10.1097/NCC.0000000000000120

[11] Martinsen K. Conversation, Judgement and the Evidence. Oslo: Akribe. 2005.

Published by Sciedu Press
[12] Måtar A. Courage in caregiving: Nursing in focus. Vård I Focus. 2008; 2: 14-17.

[13] Wein S. Is courage the counterpoint of demoralization? Journal Palliat Care. 2007.

[14] Lachman V. Moral courage: A virtue in need of development. Medsurg Nursing. 2007(a); 16(2): 131-133.

[15] Lachman V. Courage in action: case studies. Medsurg Nursing 2007(b); 16(4): 275-277. PMid:17991907 https ://doi .org/10 $.1177 / 1054773807308760$

[16] Arksey H, O>Malley L. Scoping studies: towards a methodological framework. International Journal of Social Research Methodology. 2005; 8: 19-32. https://doi.org/10.1080/13645570320001 19616

[17] Davis K, Drey N, Geould D. What are scoping studies? A review of the nursing literature. International Journal of Nursing Studies. 2009; 46: 1386-400. PMid:19328488 https ://doi.org/10.101 6/j.ijnurstu.2009.02.010

[18] Polit DF, Beck TC. Nursing Research. Lipincott Williams \& Wilkins, China. 2002.

[19] Veloso AG, Sperling C, Holm VL, et al. Unmet needs in cancer rehabilitation during the early cancer trajectory - a nationwide patient survey. Acta Oncologica. 2013; 52: 372-381. PMid:23320774 https ://doi.org/10.3109/0284186X .2012.745648

[20] Varre P, Sletteb $\varnothing$ A, Ruland C. "It's my life" Cancer patients' descriptions of ways of coping, as expressed on an online discussion forum. Vård i Norden. 2011.

[21] Merckaert I, Libert Y, Messin S, et al. Cancer patients' desire for psychological support: prevalence and implications for screening patients' psychological needs. Psycho-Oncology. 2009; 19: 141-149. PMid:19382112 https://doi.org/10.1002/pon.1568

[22] Kvåle K. Do cancer patients always want to talk about difficult emotions? A qualitative study of cancer inpatients communication needs. European Journal of Oncology Nursing. 2007; Sept; 11(4): 320-7. PMid:17446134 https://doi.org/10.1016/j.ejon.2007.01 .002

[23] Jansen J, van Weert J, van Dulmen S, et al. Patients Education About Treatment in Cancer Care An Overview of the literature on Older Patient's Needs. Cancer Nursing. 2007; 30(4): 251-260. 
PMid:17666973 https://doi.org/10.1097/01.NCC.0000281 735.25609. af

[24] Grimsbø HG, Finset A, Ruland MC. Left Hanging in the Air.Cancer Nursing. 2011; 34(2): 107-116. PMid:20921887 https://doi.or

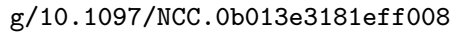

[25] Foster C, Scott I, Addington-Hall J. Who visits mobile UK services providing cancer information and support in the community? European Journal of Cancer Care. 2009; 19: 221-226. PMid:19552731 https://doi.org/10.1111/j.1365-2354.2008.01007.x

[26] Boot M, Wilson W. Clinical nurse specialists' perspectives on advance care planning conversation: a qualitative study. International Journal of Palliative Nursing. 2014; 20(1): 9-14. PMid:24464168 https://doi.org/10.12968/ijpn.2014.20.1.9

[27] Zamanzadeh V, Rassouli M, Abbaszadeh A, et al. Factors Influencing Communication Between the Patients with Cancer and their Nurses in Oncology Wards. Indian Journal of palliative Care. 2014.

[28] Waldron EA, Jake AE, Bechtel FC, et al. A systematic review of psychosocial interventions to improve cancer caregiver quality of life. Psycho-Oncology. 2013; 22: 1200-1207. PMid:22729992 https://doi.org/10.1002/pon.3118

[29] Wittenberg-Lyles E, Goldsmith J, Ferrell B. Oncology Nurse Communication Barriers to Patient - Centered Care. Clinical Journal of Oncology Nursing. 2013; 17(2): 152-158. PMid:23538250 https : //doi.org/10.1188/13. CJON.152-158

[30] Brataas VH, Thorsnes LS. Cancer nurses narrating after conversations with cancer outpatients: how do nurses' roles and patients' perspectives appear in the nurses' narratives? Scand J Caring Sci. 2009; 23: 767-774. PMid:19473315 https://doi.org/10.1111/ j.1471-6712.2008.00679.x

[31] Yoon S, Chan M, Hung WK, et al. Communicative characteristics of interactions between surgeons and Chinese women with breast cancer in oncology consultation: a conversation analysis. Health Expectations: An International Journal of Public Participation in health Care And Health Policy (Health Expect). 2014; Sep 9.

[32] Beaver K, Graven O, Witham G, et al. K. Patient participation in decision making: views of health professionals caring people with colorectal cancer. Journal of Clinical Nursing. 2007; 16: 725-733. PMid:17402954 https://doi.org/10.1111/j.1365-2702.20 $06.01587 . \mathrm{x}$

[33] Koutsopoulou S, Papathanassoglou DE. Katapodi CM, et al. A critical review of the evidence for nurses as information providers to cancer patients. Journal of Clinical Nursing. 2010; 19: 749-765.
PMid:20500319 https://doi.org/10.1111/j.1365-2702.20 $09.02954 . x$

[34] Idou M. Research on the mental health of nurses-the verification of the causal model to predict the anxiety of nurses related to cancer nursing and restructuring. Journal of Japan Academy of Nursing Science. 2002; Mar; 22(1): 1-12. https://doi.org/10.5630/ja ns 1981.22.1_1

[35] Radziewicz MR, Rose HJ, Bowman FK, et al. Establishing Treatment Fidelity in a Coping and Communication Support Telephone Intervention for Aging Patients With Advanced Cancer and Their family Caregivers. Cancer Nursing. 2009; 32(3): 193-202. PMid: 19295420 https://doi.org/10.1097/NCC.0b013e31819b5abe

[36] Zheng MC, Zhang JE, Qin HY, et al. Telephone follow-up for patients returning home with colostomies: Views and experiences of patients and enterostomal nurses. European Journal of Oncology Nursing. 2013 Apr; 17(2): 184-9. PMid:22748946 https: //doi.org/10.1016/j.ejon.2012.05.006

[37] Farrington N, Townsend K. Enhancing nurse-patient communication: a critical reflection. British Journal of Nursing. 2014; 23(14): 771775. PMid:25062311 https://doi.org/10.12968/bjon. 2014 .23 .14 .771

[38] Uitterhoeve R, Bensing J, Dilven E, et al. Nurse-patient communication in cancer care: does responding to patient's cues predict satisfaction with communication. Psycho-Oncology. 2009; 18: 10601068. PMid:19142868 https://doi.org/10.1002/pon. 1434

[39] Koinberg IL, Holmberg L, Fridlund B. Breast cancer patients' satisfaction with a spontaneous system of check-up visits to a specialist nurse. Scand J Caring Sci. 2002; 16: 2009-2015. PMid:12191031 https://doi.org/10.1046/j.1471-6712.2002.00040.x

[40] IMA A, da Silva RM, Bonfim IM, et al. Nursing communication in nursing care to mastectomized women: a grounded theory study. Revista Latino-Americana de Enfermagem. 2010; Jan-Feb; 18(1): 54-60. PMid:20428697 https ://doi .org/10.1590/S0104-116 92010000100009

[41] Liu JE, Mok E, Wong T. Caring in nursing: investigating the meaning of caring from the perspective of cancer patients in Beijing, China. Journal of Clinical Nursing. 2006; 15: 188-196. PMid:16422736 https://doi.org/10.1111/j.1365-2702.2006.01291.x

[42] De Araujo CRG, Rosas AM.Nurses' clinically-based conversation with patients and their caretakers in radiotherapy department of university hospital. Revista Enfermagem UERJ. 2008 Jul-Sep; 16(3): 364-9. 